\title{
To Study the Pattern and Prevalence of Lipid Profile Abnormality in Newly Diagnosed Type 2 Diabetes Mellitus
}

\author{
Kaushal Kumar Sinha ${ }^{1}$, Nistha Kishore ${ }^{2}$ \\ ${ }^{1}$ Senior Resident, Department of Medicine, BSA hospital, Rohini, Delhi, India, ${ }^{2}$ Senior Resident, Department of Pediatrics, BSA hospital, Rohini, Delhi, \\ India.
}

\section{Abstract}

Background: Diabetes is one of the commonest chronic non communicable disease affecting the society at large both in developing and developed countries. Present study aimed to study the Pattern and Prevalence of lipid profile abnormality in newly diagnosed type 2 diabetes mellitus. Subjects and Methods: In this study, 100 newly diagnosed cases of type 2 diabetes mellitus patients were evaluated. A cross section of both male and female diabetes patients diagnosed within the last 3 months (new onset) was taken into study. A detailed history, clinical examination and relevant investigations were performed. Collected data were analysed by using appropriate software. Results: In our study $60 \%$ were male and $40 \%$ were female. Majority of cases were in the age group of 46-55 years, followed by in age group 56-65 years. Dyslipidemia was present in $36.66 \%$ of male and $35 \%$ of female. Highest prevalence of dyslipidemia was present in $56-65$ age group. Hypertriglyceridemia was present in $33.33 \%$ of cases, Hypertriglyceridemia with low HDL-C was present in $33.33 \%$ of cases, Hypertriglyceridemia with low HDL-C and low LDL - C was present in $13.88 \%$ of cases while $19.44 \%$ were having other mixed pattern of dyslipidemia. Conclusion: Endeavour should be made to control hyperglycemia and hyperlipidia tightly by appropriate therapeutic measures so that the occurrence and worsening of complications could be mitigated.

Keywords: Dyslipidemia, hyperglycemia, lipid profile.

Corresponding Author: Dr Kaushal Kumar Sinha, Senior resident, Department of Medicine, BSA hospital, Rohini, Delhi, India.

Received: June 2019

Accepted: July 2019

\section{Introduction}

Diabetes Mellitus (D.M.) refers to a group of common metabolic disorders that share the phenotype of hyperglycemia. ${ }^{[1]}$ It results from a defect in insulin secretion and/or insulin action, which results in hyperglycaemia with disturbances of carbohydrate, fat and protein metabolism. ${ }^{[2]}$ Diabetes is one of the commonest chronic non communicable disease affecting the society at large both in developing and developed countries.

As per the 8th edition of International Diabetes Federation Atlas (2017) it is estimated that there are currently 451 million people(age 18-99) with diabetes worldwide and this number is set to increase to 693 million by the year 2045 . The major proportion of this increase will occur in developing countries of the world like India. ${ }^{[3]}$

India leads the world with largest number of diabetic subjects earning the dubious distinction of being termed the "Diabetes Capital of the World".

Type 2 diabetes is accompanied by a high prevalence of associated disorders like the various components of the metabolic syndrome like hypertension, dyslipidemia and obesity; micro vascular complications like retinopathy (Rt), nephropathy $(\mathrm{Np})$, neuropathy $(\mathrm{Nu})$ and macro vascular complications like coronary artery disease, peripheral vascular disease and cerebrovascular disease resulting in significantly high morbidity and mortality. ${ }^{[4-9]}$ The chronic complications of diabetes mellitus translate into a significant economic burden on individuals and community at large. ${ }^{[9]}$

Prior to the onset of diabetes, many patients already show metabolic abnormalities, such as dyslipidemia, further contributing to the development of complications. ${ }^{[10]}$

Type 2 diabetes mellitus is associated with the development of premature arteriosclerosis and a higher cardiovascular morbidity and mortality. ${ }^{[11-13]}$ Diabetic dyslipidemia is believed to play an important role in the pathogenesis of accelerated atherosclerosis in this condition. ${ }^{[1,15]}$ The predominant lipid abnormalities seen in diabetes mellitus are an elevated serum triglyceride (Tg) level and a low HDL-C level. ${ }^{[16]}$ Several studies have found a significant association of fasting hypertriglyceridemia and coronary artery disease(CAD) in diabetes mellitus. ${ }^{[15,17,18]}$ Present study aimed to study the Pattern and Prevalence of lipid profile abnormality in newly diagnosed type 2 diabetes mellitus.

\section{Subjects and Methods}

In this study, 100 newly diagnosed cases of type 2 diabetes mellitus patients were evaluated. A cross section of both male and female diabetes patients diagnosed within the last 3 months ( new onset) attending the general medicine indoor 
and outpatient department and other clinical departments of Katihar Medical College, Katihar was taken into study.

A detailed history, clinical examination and relevant investigations were performed as follows:-

\section{History}

Age, sex and duration of diabetes were recorded. Family history of diabetes and personal medical history was enquired. History of symptoms suggestive of diabetic complications like visual problems, abnormal sensory and motor complaints, decreased urine output and bowel and bladder abnormalities was taken.

\section{Inclusion Criteria}

\section{Patients with:}

- Newly diagnosed case of type 2 diabetes mellitus

- Cases within 3 months of diagnosis

\section{Exclusion Criteria}

Patients with:

- $\quad$ Type 1 diabetes mellitus

- Diagnosed type 2 diabetes of more than 3 months duration

- Previous history of any vascular disease

- End stage renal disease

- Preexisting neurological disease including stroke, dementia

- History of nephrotoxic, neurotoxic or oculotoxic drug use

\section{Biochemical Analysis}

Biochemical analysis of the following were done in the

Table 1: Sex Wise Distribution of Population

\begin{tabular}{|l|l|l|}
\hline Sex & Number & \% Age \\
\hline Male & 60 & 60 \\
\hline Female & 40 & 40 \\
\hline
\end{tabular}

In our study $60 \%$ were male and $40 \%$ were female

Table 2: Showing Distribution of Population in Different Age Group

\begin{tabular}{|l|l|l|}
\hline Age Groups (In Yrs) & Number & \% AGE \\
\hline $36-45$ & 14 & 14 \\
\hline $46-55$ & 51 & 51 \\
\hline $56-65$ & 35 & 35 \\
\hline
\end{tabular}

Majority of cases were in the age group of 46-55 years, followed by in age group 56-65 years.

Table 3: Showing Male and Female Distribution in Different Age Groups

\begin{tabular}{|l|l|l|}
\hline Age Groups (In Yrs) & Male & Female \\
\hline $36-45$ & 7 & 7 \\
\hline $46-55$ & 31 & 20 \\
\hline $56-65$ & 22 & 13 \\
\hline
\end{tabular}

Table 4: Showing Prevalence of Dyslipidemia in Male and Female

\begin{tabular}{|l|l|l|l|l|l|l|}
\hline SEX & $\uparrow$ TG & $\uparrow$ TG $+\downarrow$ HDL & $\uparrow$ TG $+\downarrow$ HDL $+\uparrow$ LDL & MIXED & TOTAL & PERCENT DYSLIPIDEMIA \\
\hline Male $(\mathrm{N}=60)$ & 6 & 9 & 3 & 4 & 22 & $36.66 \%$ \\
\hline Female $(\mathrm{N}=40)$ & 6 & 3 & 2 & 3 & 14 & $35 \%$ \\
\hline
\end{tabular}

Dyslipidemia was present in $36.66 \%$ of male and $35 \%$ of female

\begin{tabular}{|c|c|c|c|c|c|c|}
\hline $36-45(\mathrm{~N}=14)$ & 1 & 2 & 0 & 1 & 4 & 28.57 \\
\hline $56-65(\mathrm{~N}=35)$ & 3 & 5 & 3 & 3 & 14 & 40 \\
\hline
\end{tabular}


Highest prevalence of dyslipidemia was present in $56-65$ age group.

Table 6: Showing Pattern of Dyslipidemia among Dyslipidemics

\begin{tabular}{|l|l|l|}
\hline Pattern Of Dyslipidemia & Number Of Patients (N=36) & Percentage Of Total Dyslipidemia \\
\hline$\uparrow T G$ & 12 & 33.33 \\
\hline$\uparrow T G+\downarrow H D L$ & 12 & 33.33 \\
\hline$\uparrow T G+\downarrow H D L+\uparrow L D L$ & 5 & 13.88 \\
\hline OTHERS & 7 & 19.44 \\
\hline
\end{tabular}

\section{Discussion}

The present cross sectional study was carried out on 100 consecutive patients of type 2 diabetes who were diagnosed recently (duration less than 3 months). The mean age at diagnosis was found to be 53.7 years. This signifies that in our hospital, diabetic patients are presenting late. Among the newly diagnosed patients 60 were male and 40 patients were female.

Age wise analysis of the patients reveals that most of the patient were in age group 46-55 yrs $\mathrm{n}=51(51 \%)$, followed by in age group $56-65 \mathrm{n}=35(35 \%)$ and least number in 35 $-45 n=14(14 \%)$. This corroborates with the work done by RAMACHANDRA et al, ${ }^{[19]}$ which shows that in developing countries, the majority of diabetes patients are in the age range of 45-64 years whereas in the developed countries are aged $>65$ years .In our study $86 \%$ of population was in age group $46-65 y r s$.

$36 \%$ of newly diagnosed diabetics were having one or other type of dyslipidemia. This agrees well with the work of GUPTA et al. ${ }^{[20]}$ which reported the prevalence of dyslipidemia above $30 \%$, and CINDI (complication in newly diagnosed diabetes in India) 21 study which reported prevalence of dyslipidemia around $34 \%$. Dyslipidemia was seen in $22(36.66 \%)$ of male and $14(35 \%)$ of female at the time of diagnosis.

The classical diabetic dyslipidemia that is increased TG with reduced HDL with or without elevated LDL was present in $17(47.22 \%)$ of patients and is the commonest pattern identified in our study, this is followed by isolated increased TG seen in $12(33.33 \%)$ of patients, 7 (19.44\%) were having other mixed pattern of dyslipidemia.

\section{Conclusion}

The study was carried out with the intent to assess the prevalence of diabetic complications in the newly diagnosed type 2 diabetics and also to study the prevalence of lipid profile abnormalities in these patients and to assess the pattern of dyslipidemia in them.

Dyslipidemia was present in $36 \%$ of newly diagnosed type 2 diabetics , and the most common pattern of dyslipidemia was increased TG with reduced HDL $-\mathrm{C}$ with or without elevated LDL-C present in 47.22 \%of patients, however isolated hypertriglyceridemia was also fairly common seen in $33.33 \%$ of patients. Dyslipidemia was found to be significantly associated with nephropathy.

Endeavour should be made to control hyperglycemia and hyperlipidia tightly by appropriate therapeutic measures so that the occurrence and worsening of complications could be mitigated.

There is an urgent need for concerted efforts by Government and Non-governmental sectors to implement national programmes aimed at prevention, management and surveillance of the disease.

\section{References}

1. Harrison's principles of Internal Medicine, 20th edition 2018. P2850.

2. Hovens MMC, Van de loar FA et al. Acetylsalicyclic acid (aspirin) for primary prevention of cardiovascular disease in type 2 diabetes (protocol) Cochrane database os systematic reviews 2005, issue 3. Art no. CD005446.

3. International Diabetes Federation. The Diabetes Atlas, 8th ed. 2017. P40

4. MJ Garcia, PM McNamara, T Gordon, WB Kannel. Diabetes, 1974 , $23,105-111$

5. WB Kannel, DL McGee. Circulation, 1979, 59, 8-13.

6. J Stamler, D Wentworth, J Neaton, JA Schoenberger, D Feigal; for the MRFIT Research Group. Circulation, 1984, 70, 11-161.

7. SM Haffner; S Lehto; T Ronemaa; K Pyorala; M Laasko. N Engl J Med, 1998,339, 229-234.

8. A Juutilainen; S Lehto; T Ronnemaa; K Pyorala; M Laakso. Diabetes Care, 2008,31, 714-719

9. O Wirta; A Pasternak; J Mustonen; P Laippala; Y Lahde. Clin Nephrol, 1999, 51, 329-334.

10. LeRoith D, Fonseca V, Vinik A: Metabolic memory in diabetes-focus on insulin. Diabetes Metab Res Rev 2005, 21(2):85-90.

11. Garcia MJ, Mc Namara PM, Gordon T, Kannel WB. Morbidity and mortality in diabetics in the Framingham population ,Sixteen year follow-up study. 1974;23:105-11.

12. Fagan TC, Sowers J. Type 2 diabetes mellitus- greater cardiovascular risks and greater benefits of therapy. Arch Intern Med 1999; 159:103334.

13. Haffiner SM, Lehto'S, Ronnemaa T, Pyorala K, Laakso M.Mortality from coronary heart disease in subjects with type 2 diabetes and in non-diabetic subjects. N Eng1 J Med 1998; 339:229-34.

14. Fontbonne A. Relationship between diabetic dyslipoproteinemia and coronary heart disease risk in non-insulin dependent diabetes. Diabetes Metab Rev 1991; 7:179-89.

15. Fontbonne A, Eschewege E, Cambien F, et al.Hypertriglyceridemia as a risk factor for coronary heart disease mortality in subjects with impaired glucose tolerance or diabetes: Results from 11 year follow up of the Paris Prospective study. Diabetologia 1989; 32:300-04.

16. Taskinen M. Quantitative and qualitative lipoprotein abnormalities in diabetes mellitus. Diabetes 1992; 41:12-17.

17. Hobanson JE, Austin MA. Plasma triglyceride level is a risk factor for cardiovascular disease independent of high density lipoprotein cholesterol level: a meta analysis of population based prospective studies. J Cardiovasc Risk 1996; 3:213-19.

18. West KM, Ahuja MMS, Bennet PH, Czyzyk A, DeA costaOMD, Fuller JH, Grab B, Grabauskas V, Jarrett RJ, KusakaK, Keen H, Krolewski AS, Miki E, Schilack V, Teuschev A,Watkins PJ, Stober JA. Role of circulating glucose \& triglyceride concentrations and their interaction with other risk factors as determinants of arterial disease in nine diabetic population samples from the WHO Multicenter Study. Diabetes Care 1983;6:361-69.

19. Ramachandran A. Socioeconomic burden of diabetes in India.Suppl. JAPI 2007; 55:9

20. Gupta S, Kapse A. Lipid Profile Pattern in Diabetics from Central India Int J Diab Dev Ctries 2001;21:138-45

21. O P Gupta, Sanjeev phatak pandemic trends in prevalence of diabetes mellitus and associated coronary heart disease in india - their causes and prevention. int. j. diab. dev. countries (2003), vol. 23-42-43 
Copyright: (C) the author(s), 2019. It is an open-access article distributed under the terms of the Creative Commons Attribution License (CC BY 4.0), which permits authors to retain ownership of the copyright for their content, and allow anyone to download, reuse, reprint, modify, distribute and/or copy the content as long as the original authors and source are cited.

How to cite this article: Sinha KK, Kishore N. To Study the Pattern and Prevalence of Lipid Profile Abnormality in Newly Diagnosed Type 2 Diabetes Mellitus. Acad. J Med. 2019;2(1):1-4.

DOI: dx.doi.org/10.21276/ajm.2019.2.1.1

Source of Support: Nil, Conflict of Interest: None declared. 